\title{
Cracking the Vocabulary Code in Mathematics in the Foundation Phase
}

\begin{abstract}
To children going to school for the first time, the symbols and the vocabulary of mathematics can resemble a foreign language with its seemingly cryptic symbols and unknown terminology. This is a challenge to foundation phase learners' ability to read, write, and communicate clearly. It might be that problems of vocabulary are considered to be fairly superficial within the whole issue of language and mathematics learning, but it is nevertheless critical that such problems are not ignored in the hope that they will go away. Teachers must be purposeful in constructing learning experiences that direct learners' attention to specific words and their meaning. The aim of this article is to highlight the importance of including mathematics vocabulary code cracking as part of the pedagogical content knowledge, specifically the subdomains of knowledge of content and students, and knowledge of content and teaching, which should be addressed within foundation phase teacher preparation programmes.
\end{abstract}

Keywords: mathematics, vocabulary, strategies, techniques, pedagogical content knowledge

Carisma Nel, North-West University.E-mail: Carisma.Nel@nwu.ac.za

South African Journal of Childhood Education | 2012 2(2): 15-34 | ISSN: 2223-7674 | ๑ UJ 


\section{Introduction}

When we think of spies and secret agents, we might think of lots of things; nifty gadgets, foreign travel, dangerous missiles, fast cars and martinis being shaken, but not stirred. We probably wouldn't think of mathematics or language. But we should. Cracking codes and unravelling the true meaning of secret messages involves loads of mathematics and language.

A number of assessment studies in recent years have shown that the educational achievement of learners in South African schools is unacceptably poor. The Department of Education's (since 2010, the Department of Basic Education) systemic evaluations, conducted in grade 3 (in 2001) show very low levels of literacy and numeracy among learners. Scores for the grade 3 learners averaged 68\% for listening comprehension, but only $39 \%$ for reading comprehension and writing, and 30\% for numeracy (RSA DoE, 2003). The second cycle of systemic evaluations conducted in 2007 revealed only a limited change in learners' achievement, namely 36\% for literacy and 35\% for numeracy. The Annual National Assessments conducted in 2011 indicated that grade 3 learners (across provinces in South Africa) achieved 28\% for numeracy and 35\% for literacy, while grade 3 learners in the North West Province achieved $21 \%$ for numeracy and $30 \%$ for literacy (RSA DoBE, 2010).

The statistics mentioned above seem to indicate that our learners have not yet managed to crack the code of mathematical language. Although mathematics is visual language of symbols and numbers it is also expressed and explained through written and spoken words. For learners to excel in mathematics, they must recognise, comprehend and apply the requisite vocabulary (Aiken, 1972; Monroe \& Panchyshyn, 1995; Bay-Williams \& Livers, 2009). Thus, vocabulary instruction is as critical in mathematics as it is in the literacy classroom. Miller (1993, p. 312) states that "without an understanding of the vocabulary that is used routinely in mathematics instruction, textbooks, and word problems, learners are handicapped in their efforts to learn mathematics." Learners must understand math vocabulary if they are to master content and be able to apply it in future situations (Thompson \& Rubenstein, 2000). Maths teachers should have a vocabulary toolbox filled with gadgets (i.e., strategies and techniques) so that they can help learners crack the vocabulary code necessary to decode the maths message.

The purpose of this article is firstly, to discuss learners' mathematics vocabulary difficulties, as well as the use of vocabulary strategies and techniques being part of preservice foundation phase teachers' pedagogical content knowledge (Shulman, 1986); or what Ball, Hill \& Bass (2005) call knowledge of content and learners, and knowledge of content and teaching. Secondly, this article with review learners' mathematical vocabulary difficulties, and lastly, provide an overview of strategies and techniques (i.e., toolbox) that can be used by teachers in order to help their foundation phase learners crack the mathematical vocabulary code. 


\section{Pedagogical content knowledge: A focus on mathematics vocabulary}

Pre-service teacher training programmes play a significant role in the preparation of a highly qualified teaching work force, which is necessary to support the development of a complex $21^{\text {st }}$ century society (International Reading Association, 2003). In South Africa, the National Teacher Education Audit of 1996 concluded that the quality of teacher education was generally poor, inefficient and not cost-effective (Hofmeyer \& Hall, 1996). According to the DoHET (2011, p. 15), the quality and the relevance of the teacher preparation programmes offered by HEls, vary widely. In the Integrated Strategic Planning Framework for Teacher Education and Development in South Africa, 2011-2025, (RSA DoHET, 2011, p.3), it is stated that universities have the responsibility for ensuring that the programmes being offered are of high quality and lead to meaningful development for teachers. Teacher preparation programmes often cannot meet the challenge in preparing teachers for highly complex and increasingly diverse schools and classrooms, the challenge of keeping abreast of current developments in research and practice, the complexity of the knowledge base, and the difficulty of learning many of the skills required to enact the knowledge base (Snow, Burns \& Griffin, 1998; Ball \& Forzani, 2009).

Central to raising learner achievement in mathematics is improving the quality of mathematics teaching. Learners who receive high-quality instruction experience greater and more persistent achievement gains than their peers who receive lowerquality instruction (Rivkin, Hanushek, \& Kain, 2005; Wright, Horn, \& Sanders, 1997). Rivkin et al. (2005) found that learners who were taught by a highly effective teacher achieved a gain of 1.5 grade equivalents during a single academic year, whereas learners enrolled in classes taught by ineffective teachers gained only 0.5 grade equivalents in the same year. Moreover, the effects of high-quality instruction on the academic achievement of disadvantaged learners are substantial enough to counteract the host of familial and social conditions often found to impede learner achievement (Rivkin et al., 2005). Put differently, teachers are critical determinants of learner learning and educational progress and thus must be well trained to use effective teaching practices. However, "although many studies demonstrate that teachers' mathematical knowledge helps support increased learner achievement, the actual nature and extent of that knowledge - whether it is simply basic skills at the grades they teach, or complex and professionally specific mathematical knowledge is largely unknown" (Ball, Hill \& Bass, 2005, p. 16).

According to the National Council of Teachers of Mathematics (2000, p. 17), "[e] ffective teaching requires knowing and understanding mathematics, learners as learners, and pedagogical strategies." Teachers' mathematics knowledge is essential to effective teaching and learner learning (Ball \& Bass, 2001; Shulman, 1987). To teach effectively, teachers must possess the knowledge and skills to; a) effectively structure and present content to learners, (b) understand learners' common conceptions, misconceptions, and difficulties when learning particular content, and (c) select 
specific teaching strategies and techniques that can be used to address learners' learning needs, which derives from Shulman's original notion of pedagogical content knowledge (PCK) (Rowan, Schilling, Ball, \& Miller, 2001; Shulman, 1987).

Pedagogical content knowledge (PCK) is that distinctive knowledge domain of teaching that differentiates the expert teacher in a subject area from the subject expert. While general pedagogical knowledge can be generically applied to all teaching subjects, much of PCK is specific to individual teaching subjects. An emerging consensus is that teachers' knowledge of discipline-specific pedagogy is critical (cf. Darling-Hammond, 2000). Studies have shown that novice teachers often struggle to represent concepts in an understandable manner to their learners, because they have little or no PCK at their disposal (Kagan, 1992; Reynolds, 1992). In the teaching of mathematics, Ball (2000) stressed how the depth of teachers' understanding of mathematics PCK is a major determinant of teachers' choice of examples, explanations, exercises, items and reactions to children's work. Pedagogical content knowledge also includes an understanding of what makes the learning of specific topics easy or difficult" (Shulman, 1986, p. 9). Ball, Thames \& Phelps (2008, p. 389) state that "the continuing appeal of the notion of pedagogical content knowledge is that it bridges content knowledge and the practice of teaching." However, they also state that "the term has lacked definition and empirical foundation, limiting its usefulness." Based on their efforts to develop a practice-based theory of content knowledge for teaching, Ball et al. (2008) divided Shulman's pedagogical content knowledge into two empirically detectable subdomains, namely knowledge of content and learners (KCS), and knowledge of content and teaching (KCT). Knowledge of content and learners is knowledge that combines knowing about learners and knowing about mathematics. Teachers must anticipate what learners are likely to think and what they will find confusing. Knowledge of content and teaching combines knowing about teaching and knowing about mathematics. This knowledge requires teachers to use knowledge of mathematics to develop or choose teaching actions or moves.

Mathematics is recognised as the most difficult content area as far as reading material is considered, "with more concepts per word, per sentence, per paragraph than any other area" (Schell, 1982, p. 544). Since vocabulary represents and provides access to concepts, instruction in the vocabulary of mathematics cannot be incidental. According to Monroe (1998, p. 538), "[t]eachers need assistance in knowing how to provide meaningful vocabulary instruction in mathematics." Given the pivotal role of vocabulary, it is surprising that typically very little class time has been focused on vocabulary instruction. Researchers including Durkin (1979), Scott \& Nagy (1997), and Biemiller (2005) have documented the small present of instructional time dedicated to vocabulary teaching and the general absence of systematic, explicit vocabulary instruction. Teachers need to be able to identify learners' mathematical vocabulary difficulties and address them systematically (Rubenstein \& Thompson, 2002). This knowledge required by teachers is, therefore, part of teachers pedagogical content knowledge, and more specifically what Ball et al. (2008) have called knowledge of content and learners (e.g., identify the difficulties learners have with mathematics 
vocabulary) and knowledge of content and teaching (e.g., determining which tools can be used to address learners mathematics vocabulary difficulties).

\section{Mathematical vocabulary difficulties}

Vocabulary instruction is one of the essential elements of a learner's academic development (Snow, 2002). Although commonly associated with language proper, vocabulary proficiency is a significant contributing factor in learning and mastering mathematical concepts. Researchers have found a relationship in mathematics between vocabulary and comprehension, identifying vocabulary understanding as a key component in understanding mathematics (Miller, 1993). In examining the role that vocabulary plays in mathematical understanding, Lindgren, Roberts \& Sankey (1999, p. 16) stated that, "[m]athematics is a language. Reading a mathematics text is somewhat like reading Tolstoy's Anna Karenina in the original Russian." Adams (2003,p. 787) stated that weakness in learners' mathematics ability is often due to difficulties in reading "the language of mathematics." In other words, learning the vocabulary of mathematics is like learning a new language and learners must understand this language if they are to communicate and apply mathematics with proficiency (Monroe, 2002).

Even though some of the language used to talk about mathematics may sound familiar, because aspects of the language we use to talk about mathematics are borrowed from our everyday language (e.g., table) (NCTM, 2000; Pimm, 1987), in practice the language of mathematics can be alienating and act as a barrier. The use of everyday language in mathematics is colloquial, common and familiar, and includes conversational language (Chamot \& O’Malley, 1994; Delpit, 1998). By contrast, the register of mathematics (Halliday, 1978), which is unique to the subject, is highly formalised and includes symbols, pictures, words and numbers. Since the mathematical register is used in unique ways, it is not easily usable outside the mathematics classroom, not even in other subject classrooms (NCTM, 2000; Dahl, 2004). Consequently, the mathematical register and thus mathematical language more generally, can indeed sound, feel and look much like a foreign language, unless it is made explicit to learners.

A learner's inability to successfully minimise interference can potentially undermine his or her ability to learn. The multiplicity of representations of words in everyday language and within the mathematical register can create significant linguistics interference as learners struggle to assign appropriate meanings to words in unfamiliar contexts. As a result, developing the mathematical register can be difficult for learners unless similarities and differences are made explicit (Kotsopoulos, 2007).

There are three main ways in which children's failure to understand mathematical vocabulary may manifest: children do not respond to questions in lessons, they cannot do a task they are set and/or they do poorly in assessments/tests/exams. Their lack of response may be due to: 
Misunderstanding the spoken or written instructions. Children cannot learn the meanings of words in isolation. The use of questions is crucial in helping them to understand mathematical concepts and use mathematical terms correctly. It is important to ask questions in different ways so that children who do not understand the first time may pick up the meaning later on. Learners who have a home language (e.g., Setswana) that differs from the medium of instruction (e.g., English) will benefit from vocabulary instruction, and so will others who are not always familiar with the vocabulary and grammatical structures used in school. It is easy to use certain types of questions (e.g., recalling facts - How many days are there in a week?; applying facts - What are the factors of 42?) more often than those that require a higher level of thinking (e.g., hypothesising or predicting - Estimate the number of marbles in this jar?; designing and comparing procedures - How might we count this pile of sticks?; interpreting results - What does the graph tell us about the most common shoe size?; applying reasoning - Why is the sum of two odd numbers always even?). If teachers can use the full range of question types they will find that children begin to give more complex answers in which they explain their thinking (UK Department for Education and Employment, 2000, p. 4).

According to Abedi (2009:173):

There is a difference between language that is an essential part of the content of the question and language that makes the question incomprehensible to many learners [...] While it is important to understand and value the richness of language in an assessment system; it is also important to make sure that [...] learners [...] not be penalized for their lack of English proficiency in areas where the target of assessment is not language. Though we understand the views of some language modification critics in not "dumbing down" assessment questions by simplifying the language, we also recognize the distinction between necessary and unnecessary linguistic complexity.

In English there are many basic words, such as pronouns, prepositions, and conjunctions that make a big difference in learner understanding of mathematics problems. For example, the words of and off cause a lot of confusion in solving percentage problems, as the percent of something is quite distinct from the percent off something. The word a can mean "any" in mathematics. For example, when asking learners to "show that a number divisible by 6 is even," teachers aren't asking for a specific example, but for the learners to show that all numbers divisible by 6 have to be even. When we take the area "of" a triangle, we mean what the learners think of as "inside" the triangle. Similarly, learners often ask: why doesn't 6 divided into 12 mean the same thing as 6 divided by 12? 6 divided into 12 is 2 and 6 divided by 12 is $1 / 2$ (or 0.5 ). A study by Kathryn Sullivan (1982) showed that even a brief, three-week programme centered on helping learners distinguish the mathematical usage of "small" words can improve learners' mathematics scores. Words studied in the programme cited by Sullivan (1982) include the, is, a, are, can, on, who, find, one, ones, ten, tens, and, or, number, numeral, how, many, how many, what, write, it, each, which, do, all, same, exercises, here, there, has, and have. 
Mathematical text is lexically dense which means that it contains a minimum of redundant words, that is, contextual clues (NSW Department of School Education, 1997). Learners' attention needs to be drawn to dense phrases that contain multiple concepts which can pose difficulties to learners, for example, reflex angle, closest to, possible outcomes, exactly halfway, number sentence, per person, satisfies equations, best estimate, number line, equal length, regular hexagon, percentage decrease, square based pyramid, average daily saving, stem and leaf plot, four consecutive whole numbers, three quarter turn clockwise, sum of dots on opposite faces.

They are confused when different words may be used to describe the same concept in mathematics (cf. Table 1) or when terms are related, but learners confuse their distinct meanings (e.g., hundred and hundredths, denominator and numerator, solve and simplify, factor and multiple) (Thompson \& Rubenstein, 2000).

Table 1: Words describing the same concept

\begin{tabular}{|l|l|l|l|}
\hline \multicolumn{1}{|c|}{ Addition } & \multicolumn{1}{c|}{ Subtraction } & \multicolumn{1}{c|}{ Multiplication } & \multicolumn{1}{c|}{ Division } \\
\hline Add & Are not & By (dimension) & As much \\
\hline Altogether & Change & Double & Cut up \\
\hline And & Decreased by & Each group & Divided by \\
\hline Both & Difference & Multiplied by & Each group has \\
\hline How many & fewer & Of & $\begin{array}{l}\text { Half } \\
\text { (or other fractions) }\end{array}$ \\
\hline How much & Have left & Product of & How many in each \\
\hline In all & Left over & Times & Parts \\
\hline Increased by & How many did & triple & Quotient of \\
\hline Plus & Hot have & & Separated \\
\hline Sum & Less than & & Share \\
& & & something equally \\
\hline Together & Remain & & \\
\hline total & subtract & & \\
\hline & Take away & & \\
\hline & Taller/shorter & & \\
\hline
\end{tabular}

They are not familiar with the mathematical vocabulary found only in mathematical contexts. Teachers need to explain the mathematical vocabulary explicitly, for example, quotient, decimal, denominator, quadrilateral, parallelogram, etc.

They may be confused about mathematical terms that have different meanings in everyday English. Teachers need to recognize and make explicit the difference between 'mathematical' English and 'everyday' English (Pierce \& Fontaine, 2009; Saxe, 1988). Examples of such words are mean, volume, key, face, head, tail, range, positive, product, prime, and rule. Panchyshyn and Monroe (1992) report that more than 50\% of the general vocabulary terms used in elementary mathematics textbooks are not used frequently in other reading materials. As a result, learners are not exposed to the 
correct meanings of these words unless the teacher specifically plans for vocabulary instruction. For example, a teacher who asks, "What is the difference between 9 and 4?" could get a wide range of answers from " 9 is odd and 3 is even" to " 5 " to "one has a circle and one has a triangle." Even within mathematics words such as scale, cube and square have more than one meaning. In some cases, the same word functions as a different part of speech, for instance square can be a noun, verb or adjective.

Some mathematical phrases can cause difficulties (understanding a concept is harder when the concept is made up of the relationship between two words), for example, all numbers greater/less than X, Mary earns 5 times as much as John,, Mary is 6 years older than John, two numbers, the sum of which is 1 , etc.

They may be confused about other words which are used in everyday English and have similar, though more precise, meanings in mathematics. Words falling into this category include, average, reflection, even, edge, etc.

There are, then, practical reasons why children need to acquire appropriate vocabulary so that they can participate in the activities, lessons and tests that are part of classroom life. There is, however, an even more important reason: mathematical language is crucial to children's conceptual development. If children don't have the vocabulary to talk about division, or perimeters, or numerical difference, they cannot make progress in understanding these areas of mathematical knowledge (UK Department for Education and Employment, 2000).

\section{Providing teachers with a mathematical vocabulary toolbox}

A report from the Department for Education and Employment (UK DfEE, 1999, p. 2) in the United Kingdom stressed that "a structured approach to the teaching and learning of vocabulary is essential if children are to move on and begin using the correct mathematical terminology as soon as possible." In order to ensure that learners master critical concepts and build a solid base for learning new words, teachers should focus on helping learners crack vocabulary's CODE: connect, organise, deep process and exercise. Teachers should connect the words being introduced to what the learners already know, organise new words into meaningful categories and frameworks in order to discover relationships between terms, process the terms deelpy to internalise their meanings and exercise the words to gain ownership (Spaniak, 2009).

It is impossible to teach every word a learner should know. Teachers should prioritise vocabulary words by conducting a brief content analysis during unit planning and then organising key vocabulary into three categories, namely essential or core, important and good to know. Each category serves as a guideline for how much emphasis and time should be spent on different words.

Teachers need a repertoire of instructional techniques to teach vocabulary. Research indicates that vocabulary learning improves dramatically when learners are exposed to words multiple times and are given the opportunity to work and play with those words in a variety of ways (Marzano, 2004). In addition, different kinds of words call for different kinds of instructional techniques. Teachers should have a vocabulary 
toolbox which contains a variety of vocabulary tools and strategies that can be used to crack the CODE.

\section{Connecting tools}

During the connect phase teachers should help learners establish a connection to what they already know or what they may observe. Word walls are an ideal tool for creating a classroom culture that breeds that all important familiarity between learners and the words they encounter in their classrooms or texts (cf. Figure 1). The purpose of the mathematics word wall is to identify words and phrases that learners need to understand and use so as to make good progress in mathematics. They need to be familiar with mathematical vocabulary and mathematical terms to understand written and spoken instructions.

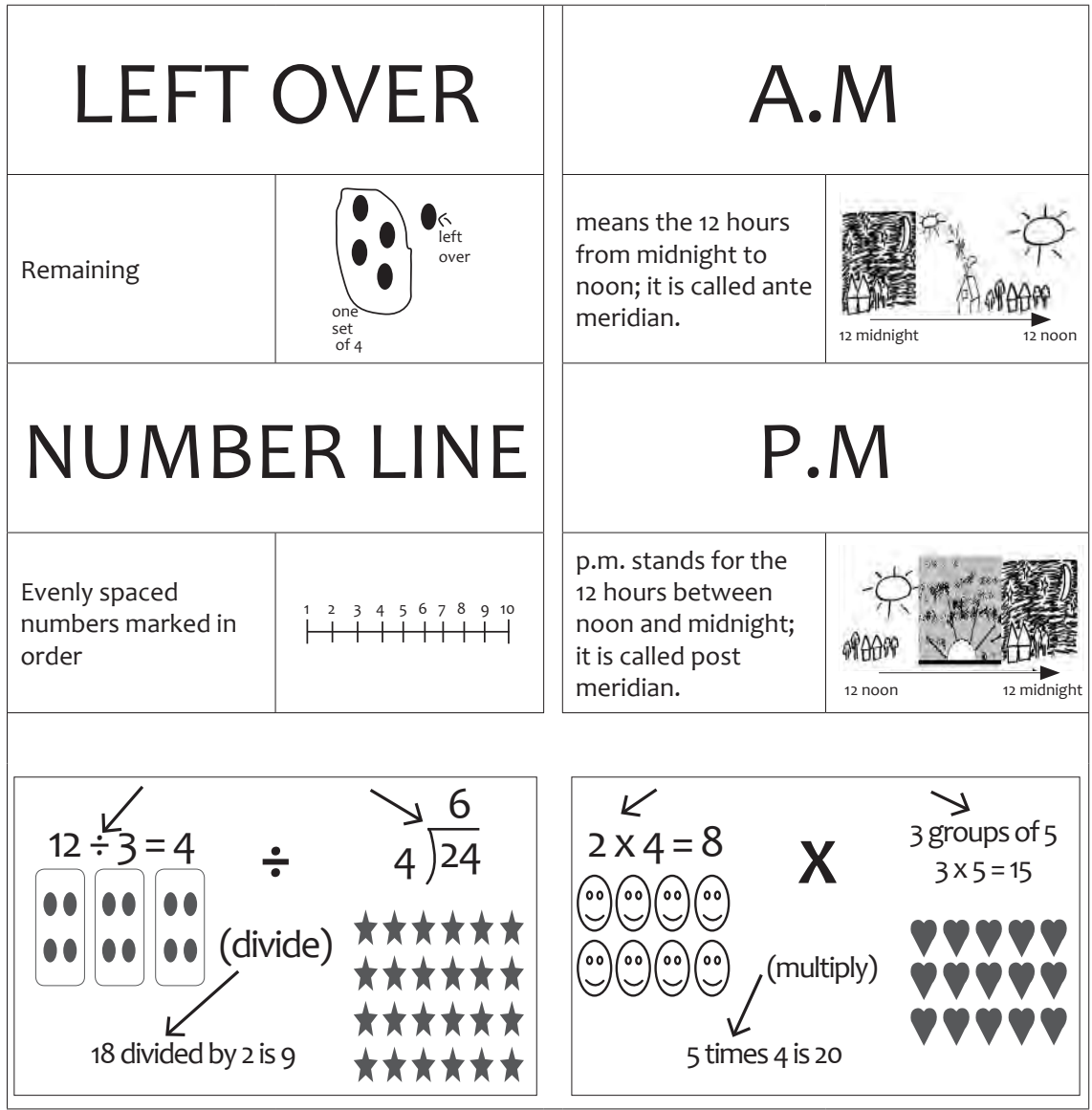

Figure 1: Word Walls (Education Quality and Accountability Office, 2012). 
A vocabulary notebook is a tool for helping learners use context clues to develop their own perspective on the meaning of difficult words. Effective word-learners attack unknown words, break them into their meaningful parts, hypothesise meanings for the larger words and then check their meanings against the context of the text as well as their own background knowledge (Anderson \& Nagy, 1992). One vocabulary instruction method that has not traditionally been associated with the foundation phase is a morphological approach; an approach that taps into the fact that a significant number of words, particularly academic words, in English are derived from Latin and Greek. Knowledge of Latin and Greek roots increases learners' ability to understand English words (Rasinki, Padak, Newton \& Newton, 2011). Research has demonstrated that many roots and affixes, including those of Latin and Greek origin, can readily be learned in the primary grades (Biemiller, 2005; Mountain, 2005). All primary-level reading instruction includes attention to phonics or word decoding (National Reading Panel, 2002; RSA DoE, 2008). Children learn to "look inside" of words for familiar letters, word families, etc. Teachers can use this foundation as a platform to help learners learn about word roots, prefixes, suffixes and base words. When it comes to teaching vocabulary, a little knowledge of root words, prefixes and suffixes goes a long way (cf. Tables 2 and 3 ).

Table 2: Root Words, Prefixes and Suffixes

\begin{tabular}{|l|l|l|l|l|}
\hline Unknown word & \multicolumn{1}{|c|}{ Root } & \multicolumn{1}{c|}{ Prefix } & \multicolumn{1}{c|}{ Suffix } & \multicolumn{1}{|c|}{ Guess meaning } \\
\hline Kilometre & Meter (measure) & Kilo (thousand) & & $\begin{array}{l}\text { Thousand } \\
\text { measures }\end{array}$ \\
\hline Percentage & Cent (hundred) & Per (through) & -age (belongs to) & $\begin{array}{l}\text { Belongs to } \\
\text { numbers through } \\
\text { a hundred }\end{array}$ \\
\hline Perimeter & Meter(measure) & Peri (around) & & $\begin{array}{l}\text { To measure } \\
\text { around }\end{array}$ \\
\hline Intersecting & Sect (cut) & Inter (between) & $\begin{array}{l}\text {-ing (result of an } \\
\text { activity) }\end{array}$ & $\begin{array}{l}\text { Result of cutting } \\
\text { between }\end{array}$ \\
\hline
\end{tabular}

Table 3: Elementary Level Latin and Greek Roots and Affixes (Rasinki et al., 2011: 136).

\begin{tabular}{|l|l|l|}
\hline \multicolumn{2}{|c|}{ Prefixes } \\
\hline a-, ab-, abs- & away, from & \\
\hline ad- & to, toward, add to & \\
\hline co-, com-, con-, col- & with, together & \\
\hline de- & own, off of & \\
\hline di-, dif-, dis- & $\begin{array}{l}\text { apart, in different } \\
\text { directions, not }\end{array}$ & \\
\hline ex- & out & \\
\hline in-, im-, il- & in, on into (directional) & \\
\hline in-, im-, il- & not (negative) & \\
\hline pre- & before & \\
\hline
\end{tabular}


Nel - CRAcking the Vocabulary Code in Mathematics in the Foundation Phase

\begin{tabular}{|l|l|l|}
\hline pro- & forward, ahead & \\
\hline re- & back, again & \\
\hline sub- & under, below & \\
\hline tra-, tran-, trans- & across, change & \\
\hline un- & not (negative) & \\
\hline
\end{tabular}

\begin{tabular}{|l|l|l|}
\hline \multicolumn{2}{|c|}{ Parallel Latin and Greek Prefixes } \\
\hline \multicolumn{1}{|c|}{ Latin } & \multicolumn{1}{c|}{ Greek } & \\
\hline Contra-, contro-, counter & anti- & against \\
\hline Circu-, circum- & peri- & around \\
\hline Multi- & poly & many \\
\hline Super-, sur- & hyper & over \\
\hline Sub- & hypo- & under, below \\
\hline
\end{tabular}

\begin{tabular}{|l|l|l|}
\hline \multicolumn{2}{|c|}{ Bases } \\
\hline Audi- audit- & hear, listen & \\
\hline Cred-, credit- & believe & \\
\hline Cur-, curs-, cours- & run, go & \\
\hline Dict- & say, tell, speak & \\
\hline Duc-, duct- & lead & \\
\hline Fac-, fic-, fact-, fect- & do, make & \\
\hline Graph-, gram- & write, draw & \\
\hline Mis-, mit- & to send & \\
\hline Mov-, mot-, mobil- & move & \\
\hline Pon-, pos-, posit- & put, place & \\
\hline Port- & carry & \\
\hline Scrib-, script & write & \\
\hline Terr- & earth & \\
\hline Vis-, vis- & see & \\
\hline
\end{tabular}

\begin{tabular}{|l|l|l|}
\hline \multicolumn{3}{|c|}{ Numerical bases } \\
\hline Uni- & one & \\
\hline Bi- & two & \\
\hline Tri- & three & \\
\hline
\end{tabular}

\begin{tabular}{|l|l|l|}
\hline \multicolumn{2}{|c|}{ Parallel Latin and Greek bases } \\
\hline \multicolumn{1}{|c|}{ Latin } & \multicolumn{1}{|c|}{ Greek } & \\
\hline Aqua- & hydro- & water \\
\hline Ped- & pod- & foot, feet \\
\hline Terr- & geo- & earth \\
\hline
\end{tabular}

\begin{tabular}{|l|l|l|}
\hline \multicolumn{2}{|c|}{ Suffixes } \\
\hline -able, ible & can, able to be done & \\
\hline -arium, -orium & place for, container for & \\
\hline -er & more & \\
\hline
\end{tabular}




\begin{tabular}{|l|l|l|}
\hline \multicolumn{2}{|c|}{ Suffixes } \\
\hline -est & most & \\
\hline -ful & full of & \\
\hline -ify & to make & \\
\hline -less & without & \\
\hline -or, -er & one who does & \\
\hline -ose, -ous, -eous, -ious & full of & \\
\hline
\end{tabular}

The root word tree is a graphic organiser that allows learners to examine a single vocabulary word for its different word parts. When using the graphic organiser learners locate an unknown word, write it at the base of the tree, and break apart the word into recognizable chunks to help them decipher its meaning (cf. Figure 2).

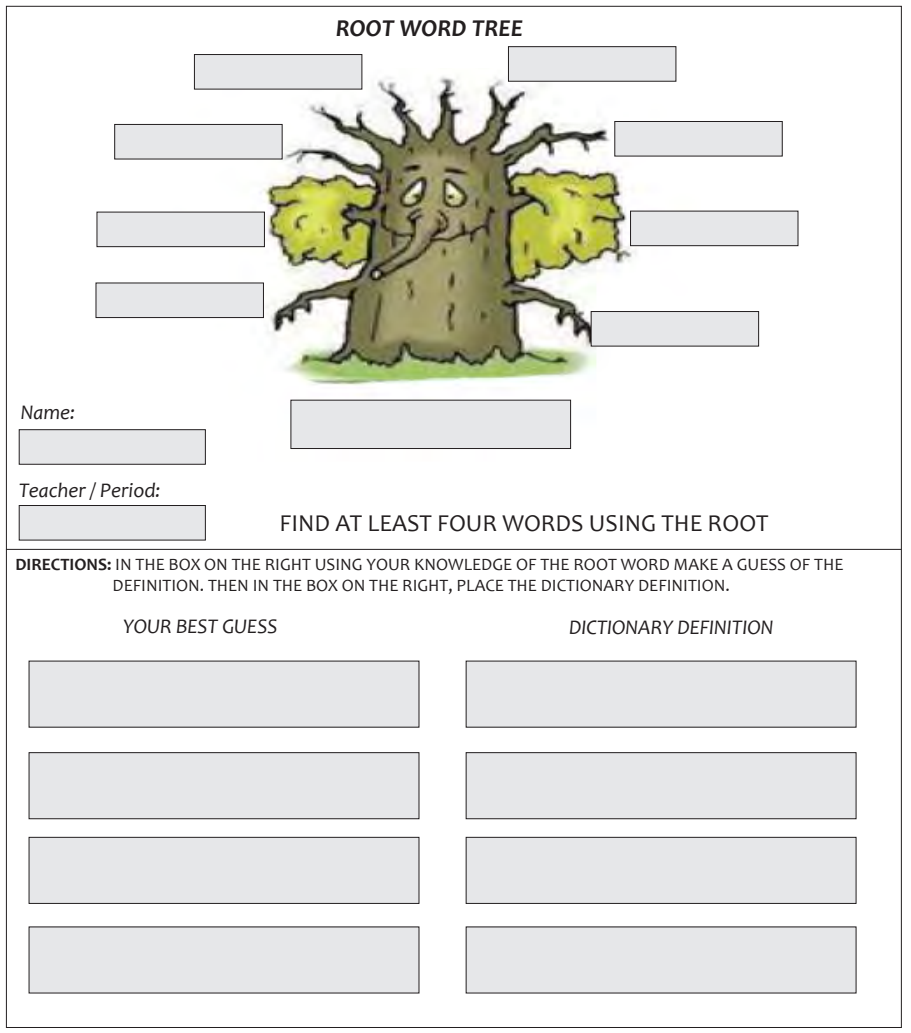

Figure 2: The Root Word Tree (McKnight, 2010).

Teach learners how to use the Four S's (See It, Say It, Spell It, Show It) to connect deeply with the new word. See the word: note its spelling and the way it looks when written. Say the word: saying the word out loud a few times forges a connection between your mouth and your brain. Spell the word: write the word out in your 
glossary, paying close attention to how it is spelled. Show the word: show your understanding with sketches and sentences you create for these words in a glossary or vocabulary journal. This tool is especially useful when the context doesn't provide any substantial information about a word's meaning.

Engage pupils in the creation of learner-created math glossaries. Provide pupils with pages marked with alphabet letters (cf. Figure 3). Instruct learners to place these sheets in the backs of their notebooks and pull them out when they learn new math vocabulary. Ask learners to add all new vocabulary terms to the glossary as they learn them. By writing these terms and their definitions, learners reinforce their knowledge of these terms.

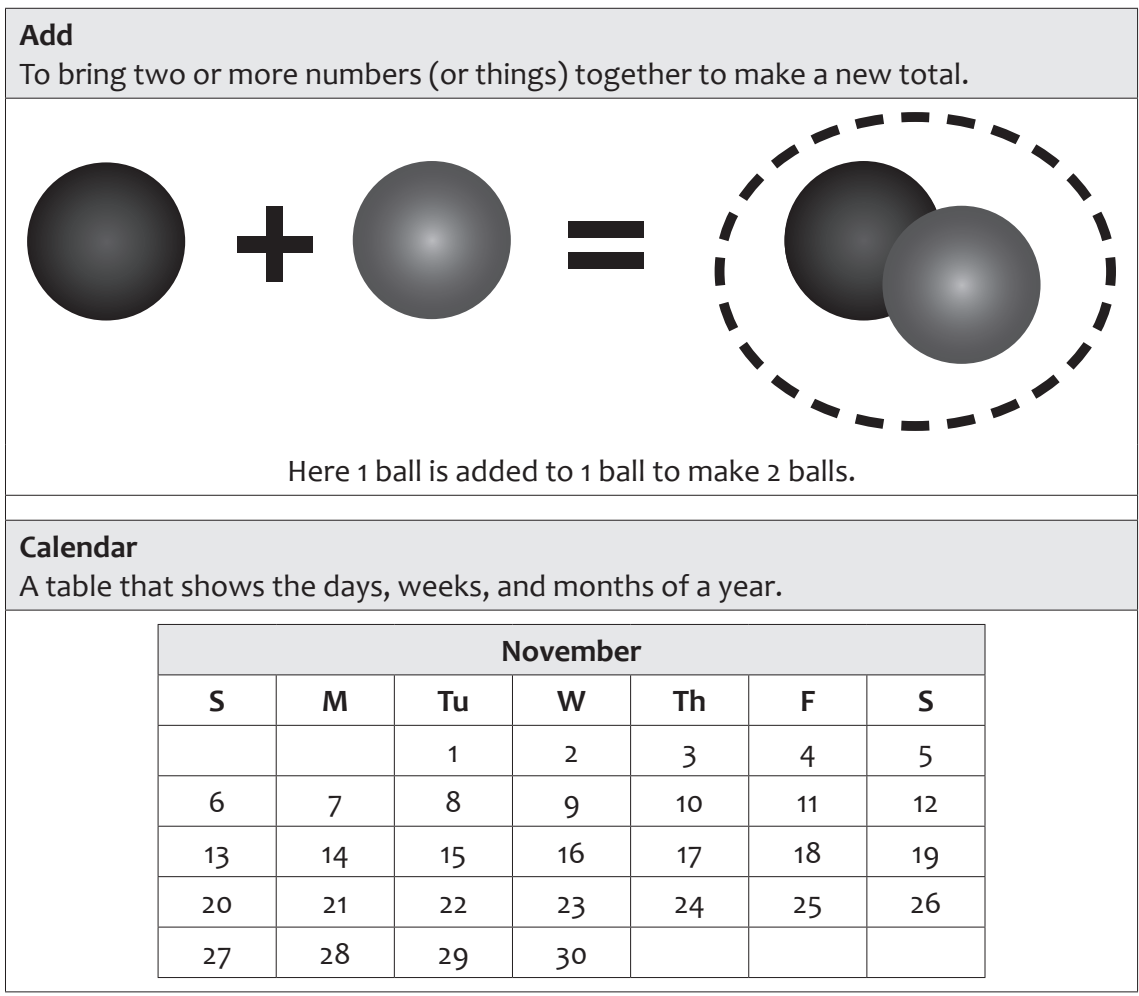

Figure 3: Glossaries

\section{Organising tools}

As the number of new words learners encounter grows, the brain creates an organisational system into which these new words can be slotted. The graphic organiser, which is closely aligned with current theory about how the brain organises information, can be used in helping learners assign deeper meaning to words 
(Monroe \& Orme, 2002). A graphic organiser represents important concepts and their relationships visually (Moore \& Readence, 1984).

Learners examine the lessons' vocabulary and place words into groups based on common characteristics. For each group learners create, they devise a label that describes what all the grouped words have in common. For example, in groups learners generate a list of terms for the word "measurement" (cf. Table 4).

Table 4: List-group-label

\begin{tabular}{|l|l|l|l|}
\hline \multicolumn{5}{|c|}{ Learner-Generated List } \\
\hline weight & height & centimetre & length \\
\hline thermometer & tape measure & scale & age \\
\hline cup & circumference & radius & meter \\
\hline area & distance & time & kilogram \\
\hline width & perimeter & ruler & temperature \\
\hline \multicolumn{5}{|l|}{ Categorise } \\
\hline Units of Measure & Things you Measure & Tools for Measurement \\
\hline centimetre & weight & ruler & \\
\hline meter & age & tape measure & \\
\hline kilogram & height & cup & \\
\hline \multicolumn{5}{|l|}{ circumference } & scale & \\
\hline & radius & thermometer & \\
\hline & area & & \\
\hline & distance & & \\
\hline & length & & \\
\hline & width & & \\
\hline & perimeter &
\end{tabular}

\section{Deep Processing tools}

Deep processing a word can mean visualising it, restating its definition in learners' own words, even acting it out or explaining their emotional response to it. Researchers emphasise the importance of vocabulary, yet also point out that knowing a word well involves the combination of several different types of knowledge. Stahl (1999) suggested that knowing a word means not only knowing its literal definition but also knowing its relationship to other words, its connotations in different contexts, and its power of transformation into various other forms. Table 5 is an example of the Frayer model and Table 6 is an example of the K-N-W-S problem solving strategy that can be used for deep processing. Learners who can master these different aspects of knowing a word have strong depth of vocabulary knowledge, and learners who are familiar with many words have breadth of vocabulary knowledge. 
Table 5: Frayer Model of Polygon

\begin{tabular}{|c|c|}
\hline $\begin{array}{l}\text { DEFINITION } \\
\text { A mathematical shape that is a closed plane } \\
\text { figure bounded by } 3 \text { or more line segments }\end{array}$ & \begin{tabular}{ll} 
& \multicolumn{1}{c}{ CHARACTERISTICS } \\
- & Closed \\
- & Plane figure \\
- & More than 2 straight sides \\
- & Two-dimensional \\
- & Made of line segments \\
\end{tabular} \\
\hline \multicolumn{2}{|c|}{ POLYGON } \\
\hline $\begin{array}{ll} & \\
\text { - } & \text { EXAMPLES } \\
\text { - } & \text { Hexagon } \\
\text { - } & \text { Square } \\
\text { - } & \text { Triangle } \\
\text { - } & \text { Rhombus }\end{array}$ & $\begin{array}{ll} & \\
& \text { NON-EXAMPLES } \\
\text { - } & \text { Circle } \\
\text { - } & \text { Arrowe } \\
\text { - } & \text { Cylinder }\end{array}$ \\
\hline
\end{tabular}

Table 6: K-N-W-S strategy

Video Pit rents movies for R3 each per night. They also offer a video club plan. The plan costs R100 per year and allows unlimited rentals at R1 per movie per night plus two free rentals per month. How many movies must you rent in a year to make the video club worthwhile?

\begin{tabular}{|l|l|l|l|}
\hline \multicolumn{1}{|c|}{ K } & \multicolumn{1}{c|}{$\mathbf{N}$} & \multicolumn{1}{c|}{ W } \\
$\begin{array}{l}\text { What facts do I KNOW } \\
\text { from the information } \\
\text { in the problem? }\end{array}$ & $\begin{array}{l}\text { Which information do } \\
\text { I NOT need? }\end{array}$ & $\begin{array}{l}\text { WHAT does the } \\
\text { problem ask me to } \\
\text { find? }\end{array}$ & $\begin{array}{l}\text { What STRATEGY/ } \\
\text { operation/tools will } \\
\text { I use to solve the } \\
\text { problem? }\end{array}$ \\
\hline
\end{tabular}

\section{Exercising tools}

To hold onto the words they learn and what these words mean, learners need to review their learning in a way that promotes high levels of retention. Teach learners how to look back on their glossaries and deepen their understanding by using the four R's: Revisiting what they've recorded, Reviewing the word's meaning, Refining their definition of the word in light of new understanding, and Revising their way of remembering the word by adding their original picture, creating a metaphor or simile, adding new examples or non-examples, providing a real-world application, etc.

Writing about thinking is challenging. For this reason, it is best not to start out having learners write about unfamiliar mathematical ideas. First get them used to writing in a math class. Have learners write a "mathograph" - a paragraph in which they describe their feelings about and experiences in math (e.g., What do you remember about learning to add and to subtract? Which did you think was more fun? Why did you like that one better?). This exercise is a good tool to get to know learners 
early in the year, and to make comparisons later when looking for signs of progress. Once learners have become accustomed to writing about their attitudes and feelings toward mathematics in their journals, they are ready to write about simple, familiar math concepts (e.g., Explain in your own words what subtraction means). When a new concept is introduced and the class looks disengaged or confused ask the learners to write an explanation of the method of calculation or a term that was used (e.g., Write down two questions you have about the work we are doing/the lesson we are working on).

\section{Conclusion}

Pedagogical content knowledge is assumed to develop as teachers gain more experience in teaching, because it is directly related to the act of teaching (Borko \& Putnam, 1996). However, studies of pre-service mathematics teachers' knowledge and skills related to teaching have revealed that methods courses and field experiences are likely to contribute to the development of PCK (Van Driel, de Jong, \& Verloop, 2002). In order to alleviate the difficulties that pre-service teachers face during their starting years, teacher educators have a responsibility to ensure that pre-service teachers acquire sufficient PCK during their preparation. When preparing pre-service teachers, they should be provided with instructional application experiences in which they can demonstrate their PCK. To achieve this, they need experience during work integrated learning sessions.

Mathematics teachers don't need to become reading specialists in order to help learners read mathematics texts, but they do need to recognize that learners need their help reading in mathematical contexts. Teachers should make the strategic processes necessary for understanding mathematics vocabulary explicit to learners. Teachers must help learners use strategies for acquiring vocabulary and reading word problems for meaning.

\section{References}

Abedi, J. (2009). Validity of assessments for English language learning learners in a national/international context. Estudios sobre Educación, 16, 167-183.

Adams, T. (2003). Reading mathematics: More than words can say. The Reading Teacher, 56, 786-795.

Aiken, L.R. (1972). Language factors in learning mathematics. Review of Educational Research, 42(3), 359-385.

Anderson, R.C., \& Nagy, W.E. (1992). The vocabulary conundrum. American Educator, 16(14-18), 44-47.

Ball, D.L. (2000). Bridging practices: Intertwining content and pedagogy in teaching and learning to teach. Journal of Teacher Education, 51, 241-247.

Ball, D. L., \& Bass, H. (2001). Interviewing content and pedagogy in teaching and learning to teach: Knowing and using mathematics. In J. Boaler (Ed.), Multiple 
perspectives on mathematics teaching and learning (pp. 83-104). Westport, CT: Ablex Publishing.

Ball, D.L., \& Forzani, F. M. (2009). The work of teaching and the challenge for teacher education. Journal of Teacher Education, 60(5), 497-511.

Ball, D.L., Hill, H.C. \& Bass, H. (2005). Knowing mathematics for teaching: Who knows mathematics well enough to teach third grade, and how can we decide? American Educator, 29(3), 14-46.

Ball, D.L. Thames, M.H., \& Phelps, G. (2008). Content knowledge for teaching: what makes it special? Journal of Teacher Education, 59, 389-407.

Bay-Williams, J.M., \& Livers, S. (2009). Supporting math vocabulary acquisition. Teaching Children Mathematics, 16(4), 239-246.

Biemiller, A. (2005). Size and sequence in vocabulary development: Implications for choosing words for primary grade vocabulary instruction. In E.L. Hiebert \& M.L. Kamil (Eds.), Teaching and learning vocabulary: Bringing research to practice. (pp. 223-242). Mahwah, NJ: Erlbaum.

Borko, H. \& Putnam, R. (1996). Learning to teach. In D.C. Berliner \& R.C. Calfee (Eds.), Handbook of educational psychology. New York: Macmillan.

Chamot, A., \& O'Malley, J.M. (1984). The CALLA handbook: Implementing the cognitive academic language learning approach. Boston: Addison-Wesley.

Dahl, B. (2004). Analysing cognitive learning processes through group interviews of successful high school pupils: Development and use of a model. Educational Studies in Mathematics, 56, 129-155.

Darling-Hammond, L. (2000). Teacher quality and learner achievement. A review of State policy evidence. Education Policy Analysis Archives, 8(1).

Delpit, L.D. (1998). Ebonics and culturally responsive instruction. In Perry, T. \& Delpit, D. (Eds.) The real ebonics debate. Milwaukee, WI: Rethinking Schools.

Durkin, D. (1979). What classroom observations reveal about reading comprehension. Reading Research Quarterly, 14, 518-544.

Education Quality and Accountability Office. (2012). Grade 3 maths resources. Retrieved 5/12/12, from http://www.esl.amdsb.ca/pdf/Grade3EQAOMathResources.pdf

Halliday, M.A.K. (1978). Language as a social semiotic: the social interpretation of language and meaning. London: Edward Arnold.

Hofmeyr, J., \& Hall, G. (1996). The national teacher education audit: Synthesis report. Pretoria: Department of Education.

International Reading Association. (2003). Investment in teacher preparation in the United States. A position statement of the International Reading Association. Newark, Delaware: IRA.

Kagan, D. M. (1992). Professional growth among pre-service and beginning teachers. Review of Educational Research, 62(2), 129-169. 
Kotsopoulos, D. (2007). It's like hearing a foreign language. Mathematics Teacher, 101(4), 301-305.

Lindgren, W., Roberts, G., \& Sankey, A. (1999). Introduction to mathematical thinking. Retrieved on December 15, 2006 from http://www.tec.iup.edu/mhogue/literary review.html.

Marzano, R.J. (2004). Building background knowledge for academic achievement: Research what works in schools. Alexandria, VA: Association for Supervision and Curriculum Development.

McKnight, K.S. (2010). The teacher's big book of graphic organizers. San Francisco, CA: John Wiley \& Sons.

Miller, D. (1993). Making the connection with language. Arithmetic Teacher, 40(6), 311- 316.

Monroe, E. (1998). Using graphic organizers to teach vocabulary: Does available research inform mathematics instruction? Education, 118(4), 538-540.

Monroe, E. (2002). Developing mathematical vocabulary. Preventing School Failure, 36(3), 139-142.

Monroe, E., \& Orme, M.P. (2002). Developing mathematical vocabulary. Preventing School Failure, 46(3), 139-142.

Monroe, E. \& Panchyshyn, R. (1995). Vocabulary considerations for teaching mathematics. Childhood Education, $72(2), 80-83$.

Moore, D.W., \& Readence, J.E. (1984). A quantitative and qualitative review of graphic organizer research. Journal of Educational Research, 78(1), 11-17.

Mountain, L. (2005). ROOTing out meaning: More morphemic analysis for primary pupils. The Reading Teacher, 58(8), 742-749.

National Council of Teachers of Mathematics (NCTM). (2000). Principles and standards for school mathematics. Reston, VA: Author.

National Reading Panel. (2000). Teaching children to read: An evidence-based assessment of the scientific research literature on reading and its implications for reading instruction. Reports of the subgroups. Retrieved February 15, 2011, from http:// nationalreadingpanel.org

NSW Department of School Education. (1997). Teaching literacy in mathematics in year 7. Sydney: Author.

Panchyshyn, R., \& Monroe, E.E. (1992). Vocabulary considerations in mathematics instruction. Paper presented at the Fourteenth World Congress on Reading, Maui, HI.

Parker, J., \& Heywood, D. (2000). Exploring the relationship between subject knowledge and pedagogic knowledge in primary teachers' learning about forces. International Journal of Science Education, 22(1), 89-111.

Pierce, M. E., \& Fontaine, L. M. (2009). Designing vocabulary instruction in mathematics. Reading Teacher, 63(3), 239-243. 
Pimm, D. (1987). Speaking mathematically: Communication in mathematics classrooms. New York: Routledge and Kegan Paul.

Rasinski, T.V., Padak, N., Newton, J., \& Newton, E. (2011). The Latin-Greek connection. Building vocabulary through morphological study. The Reading Teacher, 65, 133141.

Reynolds, A. (1992). What is competent beginning teaching? A review of the literature. Review of Educational Research, 62(1), 1-35.

Rivkin, S.G., Hanushek, E.A., \& Kain, J.F. (2005). Teachers, schools, and academic achievement. Econometrica, 73(2), 417-458.

Rowan, B., Schilling, S., Ball, D., \& Miller, R. (2001). Measuring teachers' pedagogical content knowledge in surveys: An exploratory study. Consortium for Policy Research in Education, Study of Instructional Improvement, Research Note S-2. Ann Arbor, MI: University of Michigan.

RSA DoE (Republic of South Africa. Department of Education). (2003). Systemic evaluation Foundation Phase mainstream national report. Pretoria: Department of Education.

RSA DoE (Republic of South Africa. Department of Education). (2008). Teaching reading in the early grades. A teacher's handbook. Pretoria: Department of Education.

RSA DoBE (Republic of South Africa. Department of Basic Education). (2010). Annual national assessments 2011. A guideline for the interpretation and use of ANA results. Pretoria: Department of Basic Education.

RSA DoHET. (Republic of South Africa. Department of Higher Education and Training). (2011). The minimum requirements for teacher education qualifications. Government Gazette No. 34467. Pretoria: Department of Education

Rubenstein, R. \& Thompson, D. (2002). Understanding and supporting children's' mathematical vocabulary development. Teaching Children Mathematics, 9(2), 107-112.

Saxe, G. B. (1988). Linking language with mathematics achievement. In R. R. Cocking \& J. P. Mestre (Eds.), Linguistic and cultural influences on learning mathematics. Hillsdale, NJ: Lawrence Erlbaum Associates.

Schell, V. (1982) Learning partners: Reading and mathematics. The Reading Teacher, 35(5), 544-548.

Scott, J.A. \& Nagy, W.E. (1997). Understanding the definitions of unfamiliar verbs. Reading Research Quarterly, 32, 184-200.

Shulman, L. (1986). Those who understand: knowledge growth in teaching. Educational Researcher, 15(2), 4-14.

Shulman, L. S. (1987). Knowledge and teaching: foundations of the new reform. Harvard Educational Review, 57(1), 1-22.

Snow, C. (2002). Reading for understanding: Toward an $R \& D$ program in reading comprehension. Santa Monica, California: Rand Corporation. 
Snow, C.E., Burns, S.M., Griffin, P. (1998). Preventing reading difficulties in young children. Washington, DC: National Academy Press.

Spaniak, N. (2009). The keys to unlocking vocabulary's c.o.d.e. Paper presented at the Secondary Reading League Day of Reading, November 7. Retrieved May 25, 2012 from www.dayofreading.org/DORogHO/SpaniakVocabCode.pdf

Stahl, S. (1999). Vocabulary development. Cambridge, MA: Brookline Books.

Sullivan, K. (1982). Vocabulary instruction in mathematics: Do the "little" words count? American Reading Forum Yearbook, 2, 9-11.

Thompson, D.R., \& Rubenstein, R.N. (2000). Learning mathematics vocabulary: Potential pitfalls and instructional strategies. The Mathematics Teacher, 93(7), 568-574.

UK Department for Education and Employment. (1999). The national numeracy strategy: Framework for teaching mathematics from reception to year 6. Sudbury: DfEE.

UK Department of Education and Employment. (2000). The national numeracy strategy. Mathematical vocabulary. London: DfEE.

Van Driel, J.H., de Jong, O., \& Verloop, N. (2002). The development of preservice chemistry teachers' pedagogical content knowledge. Science Education, 86, 572590.

Wright, S.P., Horn, S.P., \& Sanders, W.L. (1997). Teacher and classroom context effects on learner achievement: Implications for teacher evaluation. Journal of Personnel Evaluation in Education, 11, 57-67. 